\title{
Association Between Retinol-binding Protein and Sarcopenia in General Inpatient Older Adults: a Cross Sectional Study
}

Kai Liu

Hainan General Hospital

Ying Chen

Hainan General Hospital

Tao Liu

Hainan General Hospital

Kun Zhang

Hainan General Hospital

Yunqian Li

Hainan General Hospital

Min Zeng ( $\sim$ hnzm6868@126.com )

Hainan General Hospital

\section{Research Article}

Keywords: retinol-binding protein, Sarcopenia, Barthel-index $\geq 100$, visceral protein

Posted Date: December 10th, 2021

DOl: https://doi.org/10.21203/rs.3.rs-1130125/v1

License: (9) (i) This work is licensed under a Creative Commons Attribution 4.0 International License. Read Full License 


\section{Abstract}

Objective: This study aims to evaluate the relationship between serum retinol binding protein levels and sarcopenia in elderly general hospitalized patients.

Methods: This cross-sectional study included 682 elderly patients with Barthel-index $\geq 100$ on admission. Sarcopenia was defined according to the recently updated Asian Sarcopenia Working Group 2019 criteria. The skeletal muscle mass index was measured by dual-energy X-ray absorptiometry. Serum prealbumin, albumin, hemoglobin, blood creatinine, alanine aminotransferase, aspartate aminotransferase, and retinol binding protein are also detected. Multivariate logistic regression analysis was used to evaluate the association between serum RBP levels and sarcopenia, and to adjust for potential confounding factors.

Results:There are 105 cases of sarcopenia, 56 males and 49 females. The total prevalence of sarcopenia is $15.40 \%$ in general inpatients, of which $16.47 \%$ are males and $14.33 \%$ are females.For men and women, it was observed that the serum retinol binding protein in sarcopenia patients was significantly lower than that without sarcopenia $(24.43 \pm 8.12$ vs $29.98 \pm 9.91, P<0.001)$ and $(23.27 \pm 5.13$ vs $28.35 \pm 6.63, P<$ $0.001)$,The fully adjusted model showed that male and female low retinol binding protein participants had a $2.341(1.176,4.660)$ and 2.911(1.324-6.400) times higher risk of sarcopenia than normal retinol binding protein respectively.

Conclusion: Low levels of retinol binding protein are associated with an increased risk of sarcopenia in elderly general hospitalized patients.

\section{Introduction}

Sarcopenia is a progressive and generalized skeletal muscle disorder involving the accelerated loss of muscle mass and function that is associated with increased adverse outcomes including falls, functional decline, frailty, and mortality ${ }^{[1]}$. Malnutrition is an important cause of sarcopenia and the main target of its intervention [2]. The Asian sarcopenia working group (AWGS) recommends that for potential acute or uncontrollable medical factors that may cause sarcopenia, appropriate interventions should be given to prevent the occurrence or development of sarcopenia while treating the underlying medical factors ${ }^{[3]}$.

At present, the preferred approach to the assessment of "visceral" protein status is to measure the levels in plasma of the so-called visceral protein markers, such as transthyretin (TTR) and retinol-binding protein $(\mathrm{RBP})^{[4]}$. Decreasing concentrations of these markers indicate that protein malnutrition is worsening, while rising concentrations suggest spontaneous improvement or a favorable response to nutritional intervention. The pilot study demonstrated that these 2 markers provide important information predictive of outcomes for those they identify at risk of protein-calorie malnutrition (PCM) ${ }^{[5]}$. It is also a visceral protein secreted by the liver. In 2019, some scholars reported that plasma transthyretin was used as a biomarker of sarcopenia in elderly subjects ${ }^{[6]}$. Some scholars also reported that RBP was closely 
related to hypertension ${ }^{[7]}$, diabetes and complications ${ }^{[8]}$, coronary heart disease ${ }^{[9]}$. However, there is little evidence of the interrelationship between RBP and sarcopenia in older adults.

Therefore, the aim of the present study was to assess whether the levels of serum RBP in older adults with sarcopenia differed from those without sarcopenia and whether low serum RBP was an independent risk factor for sarcopenia in older adults.

\section{Materials And Methods}

\section{Study sample}

This cross-sectional study was conducted in the ward of the Geriatric medical center of Hainan General hospital. From November 2020 to August 2021, 903 ordinary inpatients aged $\geq 60$ years were recruited continuously. The inclusion criteria were as follows: age $\geq 60 \mathrm{y}$; Able to live independently(Barthelindex $\geq 100$ ); communication barrier-free. The exclusion criteria were as follows:

- Diseases affecting nutritional status, including thyroid insufficiency, acute inflammatory diseases, cancer, stage 4 to 5 chronic kidney disease or chronic liver disease, and malignant tumors;

- Unable to cooperate with the examination due to disability;

- There is no information on laboratory results or dual energy X-ray absorptiometry (DXA) parameters.

In the 903 patients recruited, 221 were excluded from the study (Fig. 1). Among the 221 participants, 64 refused to participate in the study, 47 could not cooperate with the physical function test, 22 suffered from acute infection and acute cardiovascular and cerebrovascular events, 32 with thyroid dysfunction,

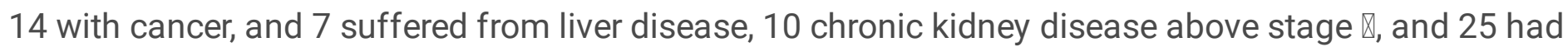
missing data.

Therefore, 682 participants (340 men and 342 women) were included in the final analysis (Figure 1).

According to the diagnostic criteria of the Asian sarcopenia working group (AWGs) ${ }^{[3]}$, participants were divided into sarcopenia group and non-sarcopenia group according to gender.

\section{Ethics statement}

The study was approved by the Medical Ethics Committee of Hainan General Hospital. Before starting data collection and physical function examination, all eligible subjects have obtained informed consent.

\section{Covariates}

This study included potential risk factors for sarcopenia based on past literature, including smoking, drinking, sports(according to the participant's self-reported exercise style, there is no time limit, including 
walking, Tai Chi, cycling, etc.), vascular complications, and nutritional markers such as BMI, albumin, prealbumin, and hemoglobin $(\mathrm{Hb})$.

\section{Demographic information and biochemical parameters}

The blood samples were collected in the morning of the second day after overnight fasting for $\geq 10$ hours. A technician from the biochemistry laboratory of the laboratory department of Hainan General hospital used standard laboratory technology to measure biochemical parameters.

Biochemical indexes included serum creatinine, serum alanine aminotransferase, aspartate aminotransferase, albumin, prealbumin, retinol binding protein and hemoglobin.

The retinol binding protein (RBP) was detected by Abbott biochemical analyzer and Dongou reagent, Zhejiang, China, Latex enhanced immunoturbidimetry, the reference value is $25-70 \mathrm{mg} / \mathrm{L}$, and the low serum RBP level was defined as $<25 \mathrm{mg} / \mathrm{L}$.

\section{Measurement: sarcopenia}

Sarcopenia is defined according to the AWGS ${ }^{[3]}$ standard, i.e. there is low muscle mass, low muscle strength or/and low physical performance. Muscle mass was assessed by DXA (Medix DR, Medilink France). All scans were performed by an experienced technician. Appendiceal skeletal muscle (ASM; kg) was calculated as the sum of the skeletal muscle mass of the arm and leg. The skeletal muscle index $(\mathrm{SMI})$ is calculated as ASM divided by the square of height $\left(\mathrm{m}^{2}\right)^{[3]}$. Low muscle mass was defined as male $\mathrm{SMI}<7 \mathrm{~kg} / \mathrm{m}^{2}$ and female $\mathrm{SMI}<5.4 \mathrm{~kg} / \mathrm{m}^{2}[3]$.

Muscle strength was assessed by grip strength (HGS) and measured using a Xiangshan electronic grip (Zhejiang, China). Participants were asked to do their best effort three times with each hand. Maximum HGS is used to diagnose Sarcopenia. According to the AWGS consensus standard, low HGS is defined as male $<28 \mathrm{~kg}$ and female $<18 \mathrm{~kg}^{[3]}$.

Gait speed $(\mathrm{m} / \mathrm{s})$ is used as a measure of physical performance during the 6-meter process. Participants

were asked to walk 6 meters at the usual walking speed ${ }^{[3]}$. Two timed tests were performed and the best performance (i.e. faster) was used to diagnose sarcopenia. Low gait speed is defined as gait speed $<1$ $\mathrm{m} / \mathrm{s}$, according to the AWGS consensus cut-off point ${ }^{[3]}$.

\section{Statistical analyses}

All statistical analyses for this study were performed using SPSS version 24 (IBM, Armonk, NY, USA). Normally distributed data was reported as mean \pm SD, whereas variables with skewed distribution were expressed as median (interquartile range). Comparisons for continuous variables were performed via the unpaired Student's $t$ test or the Mann-Whitney $U$ test. The $\chi^{2}$ test was used for categorical variables. Odds ratios (OR) were calculated using logistic regression to evaluate the intensity of the relationship between RBP and sarcopenia. This study further examined the strength of the relationship between level and grip 
strength, SMI, and physical performance by investigating the Pearson correlation coefficient. Multiple Logistic regression was performed to examine the association between RBP and sarcopenia. Covariate adjustments were investigated by the following extended model Logistic regressions: Model 1 was unadjusted; Model 2 was adjusted for age and BMI; Model 3 = Model 2+albumin, prealbumin and hemoglobin.

\section{Results}

\section{Baseline characteristics of participants}

The study included 340 men and 342 women with a mean age of $71.55 \pm 6.34 \mathrm{y}$. There are 105 cases of sarcopenia, 56 males and 49 females. The total prevalence of sarcopenia is $15.40 \%$ in general inpatients, of which $16.47 \%$ are males and $14.33 \%$ are females. Table 1 lists the clinical characteristics of the participants by gender and presence or absence of sarcopenia. BMI, SMI and walking speed were lower in both men and women with sarcopenia $(P<0.001)$, Table 1.Older men and women were more likely to have sarcopenia than younger $(P<0.001)$, Table 1 .

In addition, for men, it was observed that the serum retinol binding protein in sarcopenia patients was significantly lower than that without sarcopenia ( $24.43 \pm 8.12$ vs $29.98 \pm 9.91, P<0.001)$, BMI, albumin, prealbumin and were also significantly lower than that without sarcopenia patients, and there were statistical differences; but there was no statistical difference in hemoglobin between the two groups. For women, the serum of retinol-binding protein is also lower than that of patients without sarcopenia ( $23.27 \pm 5.13$ vs $28.35 \pm 6.63, P<0.001)$, and the BMI, prealbumin, hemoglobin and are lower than that without sarcopenia patients; but there was no statistical difference in serum albumin levels between the two groups. For both sexes, there were no significant difference in smoking, drinking, sports, hypertension, diabetes, stroke and coronary heart disease between the two groups, Table 1.

\section{Comparison of SMI, HGS, and gait speed according to Low-RBP status}

Taking the RBP value $<25 \mathrm{mg} / \mathrm{L}$ as the cut-off point, 239 patients $(35.04 \%)$ had lower RBP levels. In this group, $111(111 / 340,32.65 \%)$ are men and 128 (128/342, 37.43\%) are women. For both sexes, the Gait speed of the low RBP group was significantly lower than the normal RBP group ( $P=0.001$ and $P=0.043$, respectively), but there was no statistical difference in SMI between the two groups (Figure 2). For women, the Grip strength of the low RBP group was significantly lower than that of the normal RBP group $(P=0.004)$, but there was no statistical difference among men (Figure 2).

\section{Correlations between prealbumin levels and the components of sarcopenia}

For men, SMI, HGS, and gait speed were all positively correlated with $\mathrm{RBP}(\mathrm{R}=0.224, P \otimes 0.001 ; \mathrm{R}=0.167$, $P=0.001 ; \mathrm{R}=0.226, P \otimes 0.001$, respectively). Similarly, SMI, HGS, and gait speed were all positively correlated with $\mathrm{RBP}$ in women $(\mathrm{R}=0.159, P=0.001 ; \mathrm{R}=0.282, P \otimes 0.001 ; \mathrm{R}=0.194, P \otimes 0.001$, respectively; Table 2). 
The results of logistic regression model for the association between retinol binding protein and risk factors related to sarcopenia are shown in Table 3. Multivariate Logistic regression models included age, $\mathrm{BMI}$, albumin, prealbumin, hemoglobin and low retinol binding protein (yes or no). The fully adjusted model showed that male and female low retinol binding protein participants had a $2.341(1.176,4.660)$ and 2.911(1.324-6.400) times higher risk of sarcopenia than normal retinol binding protein, respectively, Table 3.

\section{Discussion}

The present study first investigated the relationship between retinol binding protein and sarcopenia in 682 men and women, and found that low levels of retinol binding protein is an independent risk factor for sarcopenia in older adults. After adjusting for some confounding factors, such as age, $\mathrm{BMI}$, albumin, $\mathrm{Hb}$ and prealbumin, the correlation is still significant.

The disease burden from sarcopenia arises because it is a relatively common condition and is associated with short-term and long-term adverse effects ${ }^{[1]}$. In recent years, there has been increasing interest in the potential role of visceral proteins in sarcopenia. There was evidence that sarcopenia was associated with age-related changes in visceral protein levels ${ }^{[10]}$. Muscle mass can be quantified by several body composition methods, while in contrast, the assessment of visceral protein status is more difficult.

At present, the preferred method to evaluate the status of "visceral" proteins is to measure the levels of socalled visceral protein markers in plasma, such as transthyroxine (TTR) and retinol binding protein (RBP). [11]. Recently, researchers have focused on protein status indexes involved in SM growth, maturation, and catabolism. These indexes may help identify the trajectory of sarcopenia. Ingenbleek's research suggests that visceral proteins may play a role in the pathogenesis of sarcopenia in the elderly, and may even be used as a biomarker of sarcopenia ${ }^{[6]}$.

The RBP secreted by the liver may play an equally important role in the pathogenesis of sarcopenia. Retinol-binding protein is synthesized and secreted in the liver (mostly) and other tissues (such as adipose tissue) ${ }^{[12]}$. It transports vitamin A (retinol) from the liver to target tissues and constitutes the main regulator of circulating levels of retinol. RBP is transferred in the blood together with transthyretin (TTR), which prevents kidney filtration and retinol-binding protein catabolism ${ }^{[13]}$. According to Alkharfy et al., serum RBP4 levels correlated significantly well with the existing risk factors of cardiovascular disease in women, regardless of body ${ }^{[14]}$. Another study found that retinol-binding protein is closely related to metabolic diseases and liver diseases, and these diseases are high-risk factors for sarcopenia.

It is reported that the reduction of blood protein levels also plays a role in the decline of muscle function in the elderly ${ }^{[15]}$. We have observed a decrease in serum albumin and prealbumin levels in sarcopenia patients, which is supported by some analyses ${ }^{[16-19]}$. The causality of sarcopenia is multifactorial, 
prompting comparative studies with all other LBM components to detect inconsistent evolutionary patterns. In addition, studies have confirmed that sarcopenia increases with low body mass index ${ }^{[20]}$. Our results support previous reports on $\mathrm{BMI}$ and sarcopenia. Hemoglobin is also used as a blood biomarker for malnutrition in the elderly. Previous studies have shown that low hemoglobin concentrations in the elderly in the community are associated with sarcopenia ${ }^{[21]}$. In this study, male participants with and without sarcopenia had similar hemoglobin levels, and there was no statistical difference. One possible explanation is the difference in the research subjects. The former is mainly the elderly in the community, while the general inpatients in our study are mainly.

This study has several advantages. A more reliable assessment of muscle mass through the DXA method. In addition, Sarcopenia was defined according to the latest AWGS standards, and the research objects are ordinary hospitalized patients, which are basically similar to the characteristics of the elderly in the community. But this study also has certain limitations. First, since this is a cross-sectional study, it is impossible to determine causality. Therefore, a prospective study should be conducted for a period of time. Secondly, those who cannot stay in bed for a long time and cannot live independently are excluded from this study, which may have a certain impact on the analysis of risk factors. In addition, the sample size of this study is relatively small, and the study population is selected only from a single center of Hainan General Hospital, which may not represent the general elderly population. Third, other confounding factors, such as protein intake, total calorie intake, and chronic disease drug use, are not included in the regression model.

\section{Conclusion}

Current research shows that low levels of retinol binding protein are associated with an increased risk of sarcopenia in older adults, especially in women. Therefore, a comprehensive clinical evaluation of retinol binding protein in the elderly may help early identification of people at high risk of sarcopenia. Early recognition of sarcopenia and beginning interventions for sarcopenia may improve the prognosis of hospitalized patients. Further longitudinal studies are needed to assess the association between RBP levels and the development of sarcopenia.

\section{Declarations}

\section{Ethics approval and consent to participate}

The study was conducted in accordance with the Helsinki declaration. This study was approved by the ethics committee of Hainan General hospital. Detailed information on the purpose of this study and how to use the collected data was provided to all participants. All participants obtained written informed consent before inclusion in the study.

\section{Consent for publication}

Not applicable. 
Availability of data and material

All data generated or analysed during this study are included in this published article.

\section{Competing interests}

The authors declare that they have no competing interests.

\section{Funding}

National Natural Science Foundation of China(81760054)

\section{Author Contributions Statement}

Study design and manuscript preparation: KL,YC.

Acquisition of subjects and data: YC,KZ,YL.

Analysis and interpretation: KL, TL.

Funding and critical review: MZ.

Final version manuscript preparation and approval: MZ,KL,YC.

\section{Acknowledgements}

None.

\section{References}

1. Cruz-Jentoft AJ, Sayer AA. Sarcopenia. Lancet. 2019 Jun 29;393(10191):2636-2646. doi: 10.1016/S0140-6736(19)31138-9. Epub 2019 Jun 3. Erratum in: Lancet. 2019 ;393(10191):2590.

2. Sieber CC. Malnutrition and sarcopenia. Aging Clin Exp Res. 2019 ;31(6):793-798. doi: 10.1007/s40520-019-01170-1.

3. Chen LK, Woo J, Assantachai P, Auyeung TW, Chou MY, lijima K, Jang HC, Kang L, Kim M, Kim S, Kojima T, Kuzuya M, Lee JSW, Lee SY, Lee WJ, Lee Y, Liang CK, Lim JY, Lim WS, Peng LN, Sugimoto K, Tanaka T, Won CW, Yamada M, Zhang T, Akishita M, Arai H. Asian Working Group for Sarcopenia: 2019 Consensus Update on Sarcopenia Diagnosis and Treatment. J Am Med Dir Assoc. 2020 ;21(3):300-307.e2. doi: 10.1016/j.jamda.

4. Ingenbleek Y. Plasma Transthyretin as A Biomarker of Sarcopenia in Elderly Subjects. Nutrients. 2019 21;11(4):895. doi: 10.3390/nu11040895.

5. Evans DC, Corkins MR, Malone A, Miller S, Mogensen KM, Guenter P, Jensen GL; ASPEN Malnutrition Committee. The Use of Visceral Proteins as Nutrition Markers: An ASPEN Position Paper. Nutr Clin Pract. 2021 ;36(1):22-28. doi: 10.1002/ncp.10588. 
6. Ingenbleek Y. Plasma Transthyretin as A Biomarker of Sarcopenia in Elderly Subjects. Nutrients. 2019 21;11(4):895. doi: 10.3390/nu11040895.

7. Libien J, Blaner WS. Retinol and retinol-binding protein in cerebrospinal fluid: can vitamin A take the "idiopathic" out of idiopathic intracranial hypertension? J Neuroophthalmol. 2007;27(4):253-7. doi: 10.1097/WNO.0b013e31815c44bc.

8. Wolf G. Serum retinol-binding protein: a link between obesity, insulin resistance, and type 2 diabetes. Nutr Rev. 2007 ;65(5):251-6. doi: 10.1111/j.1753-4887.2007.tb00302.x.

9. Borodkina DA, Gruzdeva OV, Belik EV, Palicheva El, Kuzmina AA. [The perspectives of application of retinol-binding protein as a biomarker of risk of cardiovascular pathology.]. Klin Lab Diagn. 2018;63(2):79-84. doi: 10.18821/0869-2084-2018-63-2-79-84.

10. Vanitallie TB. Frailty in the elderly: contributions of sarcopenia and visceral protein depletion. Metabolism. 2003 ;52(10 Suppl 2):22-6. doi: 10.1016/s0026-0495(03)00297-x.

11. Evans DC, Corkins MR, Malone A, Miller S, Mogensen KM, Guenter P, Jensen GL; ASPEN Malnutrition Committee. The Use of Visceral Proteins as Nutrition Markers: An ASPEN Position Paper. Nutr Clin Pract. $2021 ; 36(1): 22-28$. doi: 10.1002/ncp.10588.

12. Rask L, Anundi H, Böhme J, Eriksson U, Fredriksson A, Nilsson SF, Ronne H, Vahlquist A, Peterson PA. The retinol-binding protein. Scand J Clin Lab Invest Suppl. 1980;154:45-61.

13. Mangrolia P, Murphy RM. Retinol-Binding Protein Interferes with Transthyretin-Mediated $\beta$-Amyloid Aggregation Inhibition. Biochemistry. 2018 ;57(33):5029-5040. doi: 10.1021/acs.biochem.8b00517.

14. Alkharfy KM, Al-Daghri NM, Vanhoutte PM, Krishnaswamy S, Xu A. Serum retinol-binding protein 4 as a marker for cardiovascular disease in women. PLoS One. 2012;7(10):e48612. doi:

10.1371/journal.pone.0048612.

15. Xia Z, Cholewa JM, Dardevet D, Huang T, Zhao Y, Shang H, Yang Y, Ding X, Zhang C, Wang H, Liu S, Su Q, Zanchi NE. Effects of oat protein supplementation on skeletal muscle damage, inflammation and performance recovery following downhill running in untrained collegiate men. Food Funct. 2018;9(9):4720-4729. doi: 10.1039/c8fo00786a.

16. Uemura K, Doi T, Lee S, Shimada H. Sarcopenia and Low Serum Albumin Level Synergistically Increase the Risk of Incident Disability in Older Adults. J Am Med Dir Assoc. 2019 ;20(1):90-93. doi: 10.1016/j.jamda.2018.06.011.

17. Silva-Fhon JR, Rojas-Huayta VM, Aparco-Balboa JP, Céspedes-Panduro B, Partezani-Rodrigues RA. Sarcopenia and blood albumin: A systematic review with meta-analysis. Biomedica. $2021 ; 41$ (3):590603. doi: 10.7705/biomedica.5765.

18. Chen Q, Hao Q, Ding Y, Dong B. The Association between Sarcopenia and Prealbumin Levels among Elderly Chinese Inpatients. J Nutr Health Aging. 2019;23(2):122-127. doi: 10.1007/s12603-018-11305.

19. Xiu S, Sun L, Mu Z, Fu J. Low prealbumin levels are associated with sarcopenia in older men with type 2 diabetes mellitus: A cross-sectional study. Nutrition. 2021;91-92:111415. doi: 10.1016/j.nut.2021.111415. 
20. Nakanishi S, Iwamoto M, Shinohara H, Iwamoto H, Kaneto H. Significance of body mass index for diagnosing sarcopenia is equivalent to slow gait speed in Japanese individuals with type 2 diabetes: Cross-sectional study using outpatient clinical data. J Diabetes Investig. 2021 ;12(3):417-424. doi: 10.1111/jdi.13366.

21. Yoshimura Y, Wakabayashi H, Nagano F, Bise T, Shimazu S, Shiraishi A. Low Hemoglobin Levels are Associated with Sarcopenia, Dysphagia, and Adverse Rehabilitation Outcomes After Stroke. J Stroke Cerebrovasc Dis. 2020 ;29(12):105405. doi: 10.1016/j.jstrokecerebrovasdis.

\section{Tables}

Table 1. Characteristics of the participants. 


\begin{tabular}{|c|c|c|c|c|c|c|}
\hline & \multicolumn{3}{|l|}{$\operatorname{Men}(n=340)$} & \multicolumn{3}{|l|}{ Women $(n=342)$} \\
\hline & $\begin{array}{l}\text { Sarcopenia } \\
(n=56)\end{array}$ & $\begin{array}{l}\text { Non- } \\
\text { sarcopenia } \\
(\mathrm{n}=284)\end{array}$ & $\mathrm{P}$ & $\begin{array}{l}\text { Sarcopenia } \\
(\mathrm{n}=49)\end{array}$ & $\begin{array}{l}\text { Non- } \\
\text { sarcopenia } \\
(\mathrm{n}=293)\end{array}$ & $P$ \\
\hline Age(y) & $75.77 \pm 6.94$ & $71.61 \pm 5.81$ & $\begin{array}{l}\square \\
0.001\end{array}$ & $72.59 \pm 5.86$ & $70.51 \pm 6.45$ & $\begin{array}{l}\square \\
0.001\end{array}$ \\
\hline BMI & $21.59 \pm 2.33$ & $24.28 \pm 3.09$ & $\begin{array}{l}\square \\
0.001\end{array}$ & $21.08 \pm 2.51$ & $24.04 \pm 3.71$ & $\begin{array}{l}\square \\
0.001\end{array}$ \\
\hline Smoke (\%) & $14(25.00)$ & $79(27.82)$ & 0.666 & $6(12.24)$ & $16(5.46)$ & 0.158 \\
\hline Drink (\%) & $13(23.21)$ & $97(34.15)$ & 0.110 & $9(18.3)$ & $24(8.19)$ & 0.078 \\
\hline Sport (\%) & $22(39.29)$ & $103(36.27)$ & 0.669 & $16(32.65)$ & $69(23.55)$ & 0.499 \\
\hline $\begin{array}{l}\text { Hypertension, } \\
\mathrm{n}(\%)\end{array}$ & $34(60.71)$ & 184(64.79) & 0.561 & $13(26.53)$ & $46(15.70)$ & 0.205 \\
\hline Stroke, n (\%) & 11(19.64) & $76(26.76)$ & 0.265 & $9(18.37)$ & $27(9.22)$ & 0.145 \\
\hline $\begin{array}{l}\text { Coronary } \\
\text { heart disease, } \\
\text { n (\%) }\end{array}$ & $12(21.43)$ & $69(24.30)$ & 0.645 & $10(20.41)$ & $33(11.26)$ & 0.199 \\
\hline $\begin{array}{l}\text { Diabetes } \\
\text { mellitus }\end{array}$ & $21(37.50)$ & 112(39.44) & 0.786 & $21(42.86)$ & $81(27.65)$ & 0.180 \\
\hline \multicolumn{7}{|c|}{ Sarcopenia parameters } \\
\hline $\mathrm{SMI}\left(\mathrm{kg} / \mathrm{m}^{2}\right)$ & $6.21 \pm 0.38$ & $7.51 \pm 0.29$ & $\begin{array}{l}0.001 \\
0.01\end{array}$ & $4.94 \pm 0.44$ & $6.20 \pm 0.65$ & $\begin{array}{l}\square \\
0.001\end{array}$ \\
\hline $\begin{array}{l}\text { Grip strength } \\
\text { (kg) }\end{array}$ & $23.79 \pm 3.89$ & $29.91 \pm 1.69$ & $\begin{array}{l}\square \\
0.001\end{array}$ & $14.74 \pm 1.84$ & $22.04 \pm 3.07$ & $\begin{array}{l}\square \\
0.001\end{array}$ \\
\hline $\begin{array}{l}\text { Gait speed } \\
(\mathrm{m} / \mathrm{s})\end{array}$ & $0.78 \pm 0.11$ & $1.10 \pm 0.13$ & $\begin{array}{l}\square \\
0.001\end{array}$ & $0.81 \pm 0.12$ & $1.19 \pm 0.11$ & $\begin{array}{l}\square \\
0.001\end{array}$ \\
\hline \multicolumn{7}{|l|}{$\begin{array}{l}\text { Laboratory } \\
\text { results }\end{array}$} \\
\hline $\begin{array}{l}\text { Serum } \\
\text { creatinine }\end{array}$ & $72.90 \pm 8.10$ & $73.95 \pm 8.63$ & 0.218 & $70.55 \pm 7.44$ & $72.03 \pm 7.14$ & 0.412 \\
\hline ALT & $25.5 \rrbracket 16,40 \rrbracket$ & $30.5 \rrbracket 18,43 \rrbracket$ & 0.347 & $24 \llbracket 14,34 \rrbracket$ & $26 \rrbracket 15,34 \rrbracket$ & 0.999 \\
\hline AST & $25.5 \rrbracket 16,39 \rrbracket$ & $25 \rrbracket 15,39 \rrbracket$ & 0.358 & $22 \varangle 9.5,29.5 \rrbracket$ & $22 \bigotimes 14,30 \rrbracket$ & 0.488 \\
\hline Albumin $(\mathrm{g} / \mathrm{L})$ & $35.52 \pm 8.20$ & $38.51 \pm 8.25$ & 0.014 & $35.92 \pm 5.01$ & $37.05 \pm 6.06$ & 0.215 \\
\hline Prealbumin & $280.77 \pm 64.08$ & $302.26 \pm 67.88$ & 0.030 & $285.59 \pm 42.49$ & $301.56 \pm 45.82$ & 0.023 \\
\hline $\begin{array}{l}\text { Hemoglobin } \\
(\mathrm{g} / \mathrm{L})\end{array}$ & $118.64 \pm 13.64$ & $122.01 \pm 14.33$ & 0.106 & $106.69 \pm 9.85$ & $119.80 \pm 10.56$ & $\begin{array}{l}\square \\
0.001\end{array}$ \\
\hline
\end{tabular}




\begin{tabular}{|lcccccc|} 
RBP $\llbracket \mathrm{mg} / \mathrm{L} \rrbracket$ & $24.43 \pm 8.12$ & $29.98 \pm 9.91$ & $\square$ & $23.27 \pm 5.13$ & $28.35 \pm 6.63$ & $\square$ \\
\hline Low-RBP & $25(44.64)$ & $86(30.28)$ & 0.0036 & $27(55.10)$ & $101(34.47)$ & 0.006 \\
\hline
\end{tabular}

Table 2. Pearson correlation analysis between RBP and SMI, HGS, and gait speed.

\begin{tabular}{|lllll|}
\hline & Men & \multicolumn{3}{l|}{ Women } \\
\cline { 2 - 5 } & $\mathrm{R}$ & $\mathrm{P}$ & $\mathrm{R}$ & $\mathrm{P}$ \\
\hline SMI & 0.259 & $\nabla 0.001$ & 0.169 & 0.002 \\
\hline Grip strength & 0.235 & $\nabla 0.001$ & 0.246 & $\searrow 0.001$ \\
\hline Gait speed & 0.246 & $\nabla 0.001$ & 0.186 & 0.001 \\
\hline
\end{tabular}

Table 3. Logistic regression results of low retinol binding protein predicting sarcopenia in older adults.

\begin{tabular}{|c|c|c|c|c|}
\hline & & \multicolumn{3}{|l|}{ Models $^{a}$} \\
\hline & & Model $^{\mathrm{a}} 1$ & Model ${ }^{a} 2$ & Model $^{\text {a }} 3$ \\
\hline \multirow{2}{*}{$\begin{array}{l}\text { Sarcopenia } \\
\text { Men }\end{array}$} & $\begin{array}{l}\text { Odds ratio }(95 \% \\
\mathrm{Cl})\end{array}$ & 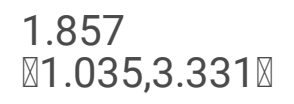 & $\begin{array}{l}2.173 \\
\otimes 1.116,4.231 \rrbracket\end{array}$ & $2.341(1.176,4.660)$ \\
\hline & $P$ & 0.038 & 0.022 & 0.015 \\
\hline \multirow{2}{*}{$\begin{array}{l}\text { Sarcopenia } \\
\text { Women }\end{array}$} & $\begin{array}{l}\text { Odds ratio }(95 \% \\
\mathrm{Cl})\end{array}$ & $\begin{array}{l}2.298 \\
\otimes 1.246,4.238 \rrbracket\end{array}$ & $\begin{array}{l}2.258 \\
\otimes 1.182,4.312 \rrbracket\end{array}$ & $2.911(1.324-6.400)$ \\
\hline & $P$ & 0.008 & 0.014 & 0.008 \\
\hline
\end{tabular}

a Adjusted covariates: Model $1=$ Unadjusted; Model $2=$ Model $1+$ age, BMI. Model $3=$ Model $2+$ ALB, Pre-ALB, hemoglobin.

\section{Figures}


903 participants (age $\geq 60$ y) with Barthel-index $\geq 100$, November 2020 to August 2021

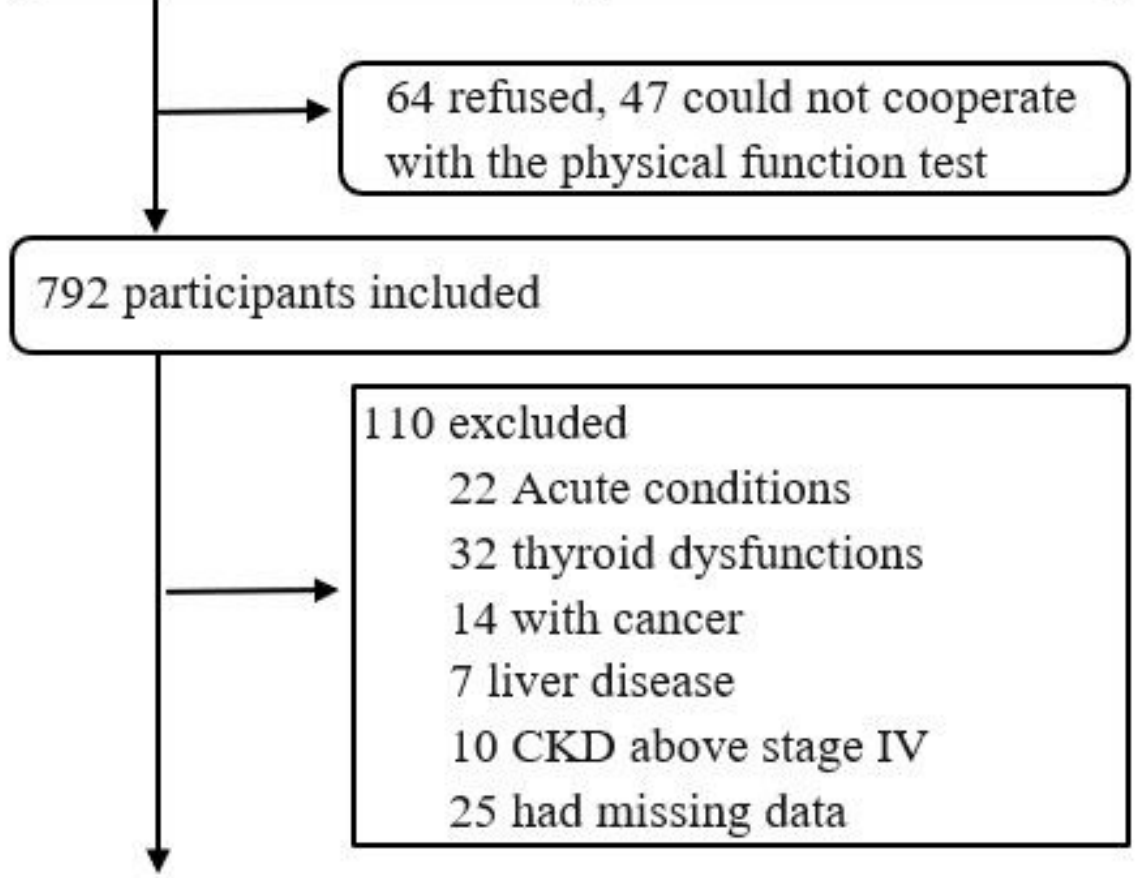

682 participants ( 340 men and 342 women) included

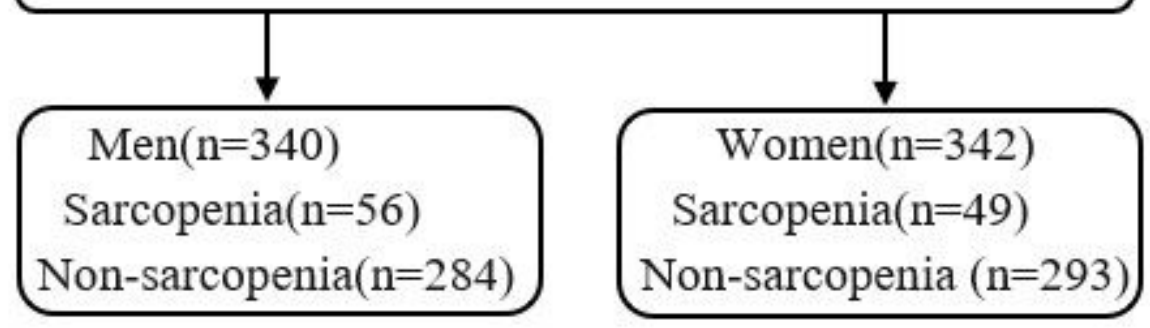

Figure 1

Flowchart on selection of participants.
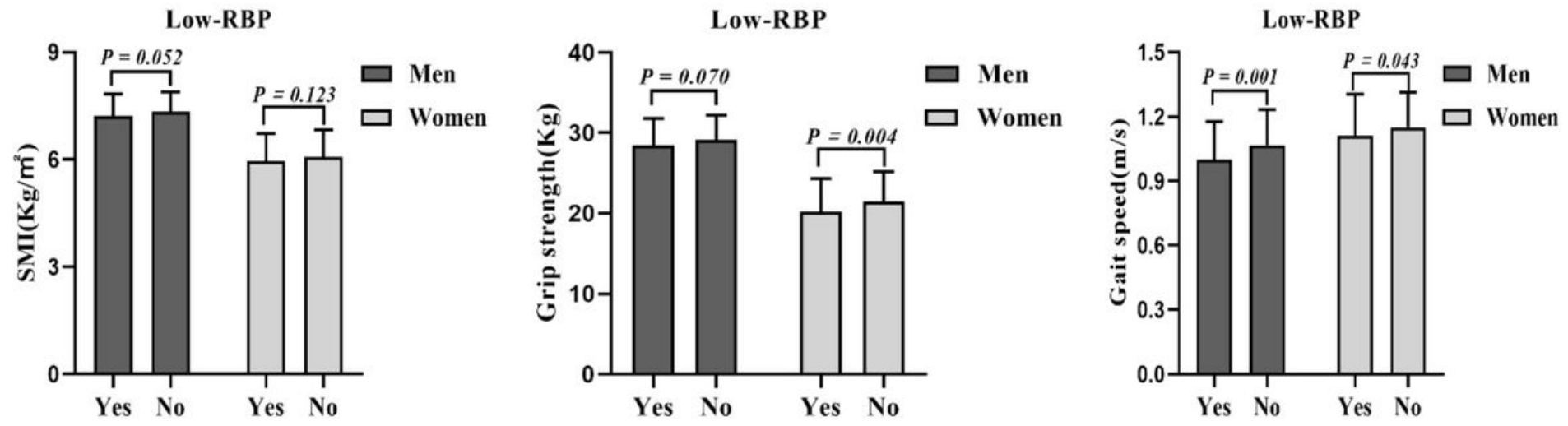

Figure 2 
SMI, HGS, and gait speed according to different RBP level. HGS, handgrip strength; SMI, skeletal muscle index. 